\title{
Direito do poeta na literatura de cordel
}

\author{
Rights of authorship for chapbooks
}

\author{
Sale Mário GAUDÊNCIO' \\ Guilherme Ataíde DIAS² \\ Maria Elizabeth Baltar Carneiro de ALBUQUERQUE²
}

\section{Resumo}

Este artigo apresenta uma análise situacional dos direitos autorais na literatura de cordel, especialmente no que se refere à proteção moral e patrimonial que é dada aos poetas populares. Justifica-se o estudo em função de não haver profundas nem atuais discussões teóricas sobre a preservação moral e patrimonial em torno das obras de cordel. Utiliza-se como metodologia a pesquisa bibliográfica relacionada a um corpus que analisa os folhetos impressos por poetas da literatura de cordel. O estudo mostra como resultados o estabelecimento de um modelo alternativo de prazos para os direitos autorais na poesia popular, além da necessidade de ruptura técnica, política e cultural. Conclui informando sobre a importância de se construir um banco de dados nacional para que se tenha conhecimento pleno do quê e como se está produzindo a literatura de cordel, além de saber quem verdadeiramente está sendo beneficiado com tais produções.

Palavras-chave: Direito autoral. Literatura de cordel. Poetas. Propriedade intelectual.

\begin{abstract}
This article presents a situational analysis of copyright in chap-book in front of the issue of copyright, especially about moral and asset protection that is given to popular poets. Is justified on the basis that there is no deep and current theoretical discussions on preserving moral and patrimonial works around the chap-book work. Has employed, as methodology to get to the proper results, a literature search that was related to a corpus that observes the leaflets in popular literature. Show as results the establishment of an alternative model of period to the copyright in popular poetry and the necessity of technical, political and cultural break. Concludes informing about the importance of building a national database so that people have full knowledge of what is being produced and how, besides to know who is truly being benefited with productions in chap-book.
\end{abstract}

Keywords: Copyright. Chap-book. Poets. Intellectual property.

\section{Introdução}

Historicamente, a literatura de cordel tem motivado uma série de estudos que visam buscar um melhor entendimento sobre o assunto: história, ascensão, declínio, formas de representação, preservação da memória e, também, a proteção aos direitos autorais.
Sua marca mais representativa se dá em torno da escrita. O cordel teve como berço o Nordeste brasileiro, sofrendo, todavia, influências da cultura ibérica trazida por meio do processo de colonização. Tem como um de seus maiores expoentes Leandro Gomes de Barros, natural do Estado da Paraíba, na região da Serra do Teixeira.

\footnotetext{
1 Universidade Federal Rural do Semi-Árido, Escola Superior de Agricultura de Mossoró, Biblioteca Orlando Teixeira. Mossoró, RN, Brasil.

2 Universidade Federal da Paraíba, Departamento de Ciência da Informação, Programa de Pós-Graduação em Ciência da Informação. Cidade Universitária, Castelo Branco, 58059-900, João Pessoa, PB, Brasil. Correspondência para/Correspondence to: G.A. DIAS. E-mail: <guilhermeataide@gmail.com>.

Recebido em 21/3/2013 e aceito para publicação em 25/4/2014.
} 
Os conteúdos informacionais frutos da literatura de cordel têm sido cotidianamente amplificados, fruto do processo de democratização das ferramentas divulgadoras do conhecimento registrado. No entanto, é cada vez mais desafiadora a ideia de garantir proteção ao titular dos direitos dos autorais da literatura popular. Para que isso ocorra, deve-se fazer o uso de instrumentos ou meios jurídicos garantidores da propriedade intelectual ao poeta popular.

Um desses instrumentos é a Lei no 9.610, de 19 de fevereiro de 1998, que "altera, atualiza e consolida a legislação sobre direitos autorais e dá outras providências" (Brasil, 1998, online). Na visão de Fragoso (2009), a temática está atrelada à ideia de Corpus Misticum e Corpus Mechanicum. Acredita-se que o maior elemento - tanto conciliador quanto separador -, na relação espírito/ matéria da propriedade Intelectual é a questão do registro, ou seja, a forma como é feita a transfiguração da ideia entre o subjetivo e o mensurável. Embora o aspecto material seja extremamente importante, é preciso fortalecer e respeitar o processo cognitivo de apreensão e comunicação em favor do registro ou transposição física, para que se tenha perpetuado o conhecimento sem substanciais "deturpações" da ideia de informação construída, mediada e propagada.

Essas ideias são ratificadas por Barbosa (2001, p.107), quando mostra que"o direito de autor, através de sua proteção direta e indireta, através dos chamados direitos conexos, protege [...] uma variada gama de produções intelectuais e artísticas: textos literários, pinturas, fotografias, música em todas as suas formas de fixação ou obras arquitetônicas para citarmos apenas alguns exemplos".

Nesse sentido, esta pesquisa busca investigar a contribuição que as questões ligadas à propriedade intelectual, especialmente os direitos autorais, podem dar à literatura de cordel e ao poeta popular, que carece de conhecimento mais profundo sobre a preservação moral e patrimonial de suas obras.

Com essa visão e a partir do campo da Ciência da Informação, pretende-se favorecer um melhor entendimento da literatura popular para a sociedade nordestina e brasileira, no que diz respeito tanto ao processo de produção quanto ao resguardo dos direitos autorais do poeta popular.
Nessa linha, este artigo tem como objetivo analisar como a literatura de cordel tem se comportado diante da questão dos direitos autorais, especialmente quanto à proteção moral e patrimonial dada aos poetas populares.

Quanto à metodologia adotada, o estudo baseia-se em pesquisa bibliográfica extraída de obras físicas e virtuais, em base de dados da Internet.

Por fim, no corpus da pesquisa, são apresentados cordelistas que produzem folhetos impressos em literatura popular.

\section{Propriedade intelectual}

Esta seção discorre sobre a propriedade intelectual, observando suas particularidades, assim como a contribuição do conceito para a questão dos direitos do autor, tema que ainda carece de maiores entendimentos e análises, sobretudo quando se trata da literatura de cordel.

Barbosa (2009, p.7), observa que a propriedade intelectual pode ser definida como:

\begin{abstract}
[...] termo correspondente às áreas do direito que englobam a proteção aos sinais distintivos (marcas, nomes empresariais, indicações geográficas e outros signos de identificação de produtos, serviços, empresas e estabelecimentos), as criações intelectuais (patentes de invenção, de modelo de utilidade e registro de desenho industrial), a repressão à concorrência desleal, as obras protegidas pelo direito de autor, os direitos conexos, enfim, toda a proteção jurídica conferida às criações oriundas do intelecto.
\end{abstract}

Considerando o exposto acima, é preciso categorizar a propriedade intelectual, observando aspectos industriais e autorais. Fragoso (2009, p.31) observa que "os direitos relacionados à propriedade intelectual no ordenamento jurídico brasileiro estão tradicionalmente segmentados em dois ramos distintos: o direito da propriedade industrial e o direito autoral".

Nesse sentido, a Organização Mundial da Propriedade Intelectual (OMPI) conhecida originariamente como World Intellectual Property Organization (WIPO) esclarece que "propriedade intelectual [...] refere-se a criações da mente: invenções, obras literárias e artísticas, 
símbolos, nomes, imagens e desenhos usados no comércio" (Organização Mundial da Propriedade Intelectual, 2013, tradução nossa, online) $)^{3}$.

Na mesma linha de pensamento,"temos incluídos no gênero propriedade intelectual os direitos relativos: a) às obras literárias, artísticas e científicas [...]" (Barbosa, 2009, p.8).

É afirmado por Fragoso (2009, p.195) que "a propriedade intelectual, hoje, é uma mercadoria". Nesse sentido, percebe-se que a obra é mais importante que o autor. Entende-se, a partir dessa visão, que em muitos casos os aspectos patrimoniais se sobrepõem aos morais, onde se torna cada vez mais difícil proteger uma obra e seu criador.

Dessa maneira,

[...] cabe analisar de que modo a propriedade intelectual opera para garantir inovação, crescimento e lealdade empresarial, sem descuidar do estudo dos fatores essenciais e necessários para que a propriedade intelectual não se torne um obstáculo ao desenvolvimento (Barbosa, 2007, p.38).

Corroborando este pensamento, Wachowicz e Santos (2010, p.83) informa:

[...] direitos de propriedades intelectuais passam necessariamente pela percepção de sua importância para a manutenção das pessoas que participam da criatividade cultural, ou seja, tais direitos devem atuar em benefício de todos os envolvidos no processo de criação, principalmente daqueles que efetivamente criam, e não somente daqueles que comercializam, promovem e divulgam.

O assunto propriedade intelectual é controverso e complexo. Isso fica ainda mais evidente quando se trata de questões que envolvem a ideia, a criação, o criador e a comercialização. O material e o imaterial, o espírito e o físico são cada vez mais evidentes nesse debate. Essa complexa relação se explica pelo fato de que as leis, sejam elas de propriedade industrial ou direitos autorais, têm sempre que observar os diversos interesses envolvidos, no caso, tanto dos produtores culturais quanto dos consumidores culturais.
Nesse sentido, fala-se em Corpus Misticum (corpo espiritual) e Corpus Mechanicum (corpo físico). Na visão de Fragoso (2009, p.40), esses aspectos são melhores compreendidos quando se percebe que:

A simples criação que permanece na mente do criador serve, tão-somente, para seu próprio deleite [...], como o próprio ato de criar. A criação que, por qualquer forma, meio ou processo não for exteriorizada, não é obra, posto não poder ser perceptível no mundo físico, e, por isso, simplesmente não existe. Impõe-se, para que se torne uma obra que, de alguma forma, se exteriorize materialmente, que se torne fenômeno, manifestado no tempo ou no espaço, perceptível pelos sentidos. De certo modo, sequer há criação se não houver exteriorização. O fenômeno da exteriorização da obra de arte pode ocorrer tanto em caráter transitório, volátil, como de modo permanente. Uma locução, declamação, recitação, mesmo uma peça de teatro, um cântico, enfim, todas essas formas dirigidas a outrem, de uma só vez ou repetidas vezes, que não tenham sido, de algum modo fixado em algum suporte material (corpus mechanicum), são obras que se perdem, ou vivem apenas na tradição oral, submetidas a modificações de toda ordem pela sua transmissão ao longo do tempo.

Então, o Corpus Misticum ou corpo espiritual é tudo aquilo que é idealizado, que está na mente, enquanto o Corpus Mechanicum ou corpo físico é tudo aquilo que pode ser exteriorizado e disponibilizado por meio de um suporte qualquer, seja ele tradicional, como um livro, seja ele virtual, como as bases de dados.

Aliado a isso, tem-se a relação sistêmica entre direito patrimonial e direito moral, cujas características são fundamentais a um dimensionamento equitativo entre a obra, o autor e o mercado, sempre sob a cobertura da lei.

Os direitos morais são irrenunciáveis e inalienáveis, isto é, não podem ser vendidos a outrem. A lei apresenta uma relação de direitos morais, em seu artigo 24:

I - o de reivindicar, a qualquer tempo, a autoria da obra;

II - o de ter seu nome, pseudônimo ou sinal convencional indicado ou anunciado, como sendo o do autor, na utilização de sua obra;

\footnotetext{
${ }_{3}$ Texto original: "Intellectual Property (IP) refers to creations of the mind: inventions, literary and artistic works, and symbols, names, images, and designs used in commerce".
} 
III - o de conservar a obra inédita;

IV - o de assegurar a integridade da obra, opondo-se a quaisquer modificações ou à prática de atos que, de qualquer forma, possam prejudicá-la ou atingi-lo, como autor, em sua reputação ou honra; $\checkmark$ - o de modificar a obra, antes ou depois de utilizada;

VI - o de retirar de circulação a obra ou de suspender qualquer forma de utilização já autorizada, quando a circulação ou utilização implicarem afronta à sua reputação e imagem;

VII - o de ter acesso a exemplar único e raro da obra, quando se encontre legitimamente em poder de outrem, para o fim de, por meio de processo fotográfico ou assemelhado, ou audiovisual, preservar sua memória, de forma que cause o menor inconveniente possível a seu detentor, que, em todo caso, será indenizado de qualquer dano ou prejuízo que the seja causado (Brasil, 1998, online).

Na mesma linha, os artigos subsequentes garantem os direitos morais dos produtores de obra audiovisual e autores de projeto arquitetônico.

Complementarmente, o capítulo seguinte trata dos direitos patrimoniais do autor (artigos 28 a 45), estes sim de expressão econômica, como a autorização para que outra pessoa utilize sua obra.

Assim, percebe-se que os direitos morais estão preocupados em proteger a obra frente ao autor, enquanto os direitos patrimoniais voltam-se ao processo de comercialização e transferência de recursos, oriundos das obras protegidas, sob a permissão do autor intelectual do produto, agora exteriorizado e manifestado através de algum suporte ou mecanismo possibilitador de divulgação.

Ao observar os elementos constituintes dos direitos morais e patrimoniais em face da propriedade intelectual, vale a pena adentrar com mais profundidade a questão dos direitos autorais, especialmente em torno da amplitude de sua proteção.

\section{Direitos autorais}

O direito do autor é parte integrante e singular da propriedade intelectual.Tem, ainda, extrema relevância para ditar as regras em torno dos direitos e deveres que garantem a dinâmica moral e patrimonial do criador, contemplada na Lei no 9.610, de 19 de fevereiro de 1998 (Brasil, 1998, online).

Com isso, a promulgação dessa lei, em consonância com o Direito Internacional e a Carta Magna Brasileira, consolida as regras e condutas necessárias para resguardar o autor e suas criações. A referida Lei de Direitos Autorais protege

Art. $7^{\circ}[. .$.$] as criações do espírito, expressas por$ qualquer meio ou fixadas em qualquer suporte, tangível ou intangível, conhecido ou que se invente no futuro, tais como:

I - os textos de obras literárias, artísticas ou científicas;

II - as conferências, alocuções, sermões e outras obras da mesma natureza;

III - as obras dramáticas e dramático-musicais;

IV - as obras coreográficas e pantomímicas, cuja execução cênica se fixe por escrito ou por outra qualquer forma;

V - as composições musicais, tenham ou não letra; $\mathrm{VI}$ - as obras audiovisuais, sonorizadas ou não, inclusive as cinematográficas;

VII - as obras fotográficas e as produzidas por qualquer processo análogo ao da fotografia;

VIII - as obras de desenho, pintura, gravura, escultura, litografia e arte cinética;

IX - as ilustrações, cartas geográficas e outras obras da mesma natureza;

$X$ - os projetos, esboços e obras plásticas concernentes à geografia, engenharia, topografia, arquitetura, paisagismo, cenografia e ciência;

$\mathrm{XI}$ - as adaptações, traduções e outras transformações de obras originais, apresentadas como criação intelectual nova;

XII - os programas de computador;

XIII - as coletâneas ou compilações, antologias, enciclopédias, dicionários, bases de dados e outras obras, que, por sua seleção, organização ou disposição de seu conteúdo, constituam uma criação intelectual [...] (Brasil, 1998, online).

Ao enumerar uma série de obras intelectuais, a Lei de Direitos Autorais deixa claro que esta enumeração é apenas exemplificativa, e não taxativa, como se depreende da expressão "tais como", que encabeça aquela lista. Seja por esse viés, seja ainda por ser o cordel um 
gênero reconhecido como literário, o fato é que ele é legalmente protegido.

\section{Literatura de cordel}

Ao iniciar a discussão sobre o cordel, vale salientar que, nas últimas décadas, têm-se solidificado estudos de caráter epistemológico que fortalecem a história, os lugares de memória e a forma como o cordel se manifesta e se estrutura.

Historicamente, tais postulados têm início com a adoção, no Brasil, do termo "cordel", como explica Câmara Cascudo:

Denominação dada em Portugal e difundida no Brasil depois de 1960, referente aos folhetos impressos compostos pelo Nordeste e presentemente divulgados e correntes em todo o Brasil. [...] No Brasil diz-se sempre Folhetos referindo-se a estas brochurinhas em versos. Um título genérico não conheço. Em Portugal dizem "Literatura de Cordel" porque os livrinhos eram expostos à venda cavalgando um barbante, como ainda acontece em certos pontos do Brasil. [...]. Em Portugal a inicial pertence a Teófilo Braga, Os Livros Populares Portugueses, Folhas-volantes ou Literatura de cordel, Era Nova, Lisboa, 1881. A maioria desses folhetos emigrou para o Brasil, ingressando no patrimônio oral. [...] A característica da Literatura de Cordel é sua destinação gráfica, circulando em opúsculos impressos, desde a segunda metade do séc. XIX, Jamais vi folheto anterior a 1870. [...] não pertence à Literatura Oral [...] (Cascudo, 2012, p.398, grifo do autor).

A partir dos elementos históricos e contextuais levantados, o trabalho recente de Albuquerque (2011, online) aprofunda a análise sobre o folheto de cordel, dando novas e significativas contribuições ao estudo da poesia popular. Com efeito, observa-se que cada vez mais o cordel tem sido objeto de estudo de inúmeras pesquisas acadêmicas, fazendo com que essa modalidade literária se fortaleça e se torne mais próxima dos leitores, da ciência e da própria literatura brasileira.

Entretanto, entre conexões próximas e díspares, é possível perceber que a literatura de cordel sofre influências tanto positivas quanto negativas. Nesse entremeio, surgem as adaptações, reformulações e releituras de obras que, ao serem lidas, geram novos textos, por vezes desconexos textos da realidade em que foram originalmente concebidos. Ao extremo, pessoas são difamadas e textos adulterados, demandando um longo processo para tentar proteger determinada obra ou a moral de determinado autor.

Por isso, acredita-se que, à luz do direito autoral, talvez se encontrem respostas para esta questão ainda presente nos porões das análises literárias.

\section{Direito autoral na literatura de cordel}

Historicamente, os poetas de cordel sempre tiveram que conviver com o problema do plágio, desafiando seus direitos de autoria. Os donos das tipografias contratavam cordelistas que não tinham recursos financeiros para publicar, distribuir nem comercializar os folhetos. Conforme estes eram impressos, o proprietário da tipografia pagava ao autor por ele ter escrito o cordel. Consequentemente, ao pagar o cordel, este se tornava propriedade do tipógrafo, o qual, por sua vez, transformava-se em autor.

Franklin Maxado relata com detalhes as relações entre o poeta, a tipografia e o folheto:

Quando havia fatos de grande repercussão, dava ensejo de se escrever o folheto rapidamente. Reuniam-se os poetas da folheteria e era dado o tema. A melhor estória era a publicada. Mas, às vezes, o dono-mestre fazia uma espécie de compilações e acrescentava seus versos, publicando o folheto em seu nome. O mestre também escrevia versões de estórias tradicionais, como a de João de Calais, ou de romances e livros famosos. Outras vezes, ele comprava os direitos de publicação de um poeta popular e a publicava em seu nome. O pagamento era quase sempre os folhetos. Entendia que os direitos autorais eram os mesmos dos direitos de propriedade. Pagou, é autor. João Martins d'Athayde, apesar de bom poeta, fez muito isso. Daí, ter os quase 4000 títulos publicados. Outro editor e poeta, Olegário Pereira Neto, de Fortaleza, chegou a colocar este aviso na contracapa do romance 'O Amor de Emília e a Ingratidão de Eduardo' por ele publicado: 'Ninguém se admire da minha firma nos livros de Luis da Costa Pinheiro porque comprei e registrei' (Maxado, 2012, p.55). 
Pelo que demonstra o cordelista, havia e ainda há um pleno desconhecimento quanto ao direito moral e patrimonial do autor. O direito moral jamais pode ser editado, especialmente quando se tratar de nome do autor que tenha sido retirado para se colocar o nome da pessoa que imprimiu e pagou pela obra. Quanto ao direito patrimonial ou de propriedade, havendo cessão de direitos, o tutor da obra poderá comercializá-la, distribuí-la e divulga-la, porém sem alterar o texto ou a autoria. Sua relação com a obra visará apenas e exclusivamente ao lucro comercial.

Outra questão autoral a ser enfrentado é o plágio, compreendido por Silva (2008, online) como apropriação de linguagem e ideias do outro, caracterizando violação da propriedade intelectual.

Observando a questão do plágio e da vulnerabilidade do texto em cordel, parte dos cordelistas tem tentado criptografar suas obras por meio da técnica dos acrósticos. Estes, na visão de Tavares (2008, online), devem ser entendidos como uma forma

[...] geralmente em verso, em que certas letras em posições especiais devem ser lidas em seqüência, formando uma ou mais palavras. O acróstico é uma variante da técnica a que chamamos "acrônimo", que utiliza este mesmo processo para a formação de siglas. No caso do acróstico, o uso mais frequente se dá com as letras iniciais dos versos de um poema. Lidas verticalmente (muitas vezes elas vêm destacadas em itálico ou negrito, para forçar essa leitura), formam um texto qualquer. [...] Muitas vezes se usa como homenagem explícita ou disfarçada. [...] Os acrósticos comuns têm a vantagem de usarem apenas a primeira letra de cada linha, e assim ficam mais fáceis de ser lidos verticalmente. São assim os acrósticos usados na literatura de cordel como assinatura disfarçada. Na última estrofe, o autor insere um acróstico de seu próprio nome como carimbo de autoria. [...] Pode parecer bobagem, mas os exemplos [...] dos cordelistas [...] mostram que é possível encriptar um texto sem muita dificuldade, e de maneira imperceptível a uma leitura casual, ou mesmo a uma procura atenta. Os acrósticos do cordel deixaram de ser úteis quando todo mundo tomou conhecimento deles - quando alguém pretendia republicar o texto como seu, bastava-lhe alterar ou suprimir o acróstico final. [...] Mas se o acróstico vier sob outra forma de camu- flagem [...], dificilmente um plagiador ou pirata saberá onde mexer para eliminar a assinatura que o verdadeiro autor deixou ali encriptada.

Por meio do acróstico, busca-se criptografar ou camuflar o texto para torná-lo menos vulnerável a agentes externos.

Nesse sentido, tem-se constatado que o cordel ainda apresenta inúmeros desafios, seja quanto à preservação dos direitos do autor, seja quanto à divulgação da obra, especialmente nos dias atuais, em que vem crescendo o número de folhetos publicados, assim como sua aceitação pela sociedade.

Além do desrespeito ao direito autoral, outros aspectos da produção literária constituem um desafio para o poeta popular.

Dentre tais questões, destaca-se a obrigação de depositar um exemplar da obra junto à Biblioteca Nacional:

Definido como a obrigação do envio de exemplares das obras publicadas em um país para uma instituição depositária, as instruções sobre depósito legal existem não só no Brasil, mas em diversos outros países como Portugal, Espanha, Polônia e Estados Unidos (Grings \& Pacheco, 2010, p.79, online).

Todavia, no campo da literatura de cordel, tal depósito apenas terá lugar se o autor, ou a editora responsável, tiver conhecimento (e consciência) de que é preciso fazê-lo.

Paradoxalmente, o fato é que o autor, inclusive o poeta popular, na maioria das vezes, não tem a informação de que é importante que a sua obra seja encaminhada para Biblioteca Nacional. Se houvesse um banco de dados com o registro de todos os depósitos efetuados, seria bem mais simples desenvolver um mapeamento do poeta popular no Brasil. Tem-se, assim, um cenário desafiador, especialmente para despertar no autor a importância do depósito.

Outra questão que merece debate diz respeito ao contrato de cessão de direito autoral:

No contrato de cessão, que deve ser escrito, os direitos de autor podem ser transferidos total ou parcialmente, presumindo-se a onerosidade. A cessão poderá ser averbada à margem do registro; não estando a obra registrada, o instrumento 
poderá ser registrado em Cartório de Títulos e Documentos. Constarão do instrumento de cessão como elementos essenciais seu objeto e as condições de exercício do direito: tempo, lugar e preço. Diferentemente do contrato de edição, não há necessidade de prever a quantidade de exemplares em que a obra será eventualmente reproduzida. A omissão do nome do autor, ou de coautor, na divulgação da obra não presume o anonimato ou a cessão de seus direitos. A cessão dos direitos de autor sobre obras futuras abrangerá, no máximo, o período de cinco anos. 0 prazo será estabelecido em cinco anos sempre que indeterminado ou superior, diminuindo-se, na devida proporção, o preço estipulado (Pierre, 2009, p.4, online).

As considerações acima mostram que ainda há muito por fazer. Os cordelistas que editam ou imprimem suas produções por meio de gráficas ou editoras, e deixam a cargo delas o processo de distribuição e venda, precisam conhecer melhor as etapas editorais. Muitas vezes, as regras não estão claras ou o autor não chega a receber nem $10 \%$ do que foi produzido, nem em espécie nem em obras impressas.

Uma alternativa seria fortalecer uma cadeia produtiva onde tudo ocorresse exclusivamente por meio do autor, ou seja, sem intermediação de terceiros. Para isso, seria necessário um capital de giro significativo para tornar o negócio viável. Contudo, o que ocorre é que, na maioria das vezes, o poeta popular não tem informações nem os recursos necessários para empreender um negócio como esse, especialmente que gere retorno financeiro e seja eficiente. São pouquíssimas as experiências em que o cordel de fato é uma fonte de sobrevivência para o poeta e seus dependentes. Muitas vezes um cordel impresso apenas dá para garantir a produção do próximo. Essas condições condenam o cordelista a ficar submisso aos ambientes reprodutores.

Além disso, o poeta popular, em muitos casos, não acredita que sua obra possa estar protegida por uma Lei de Direitos Autorais. Tampouco entende que tem direito financeiro a um percentual da obra. Mais ainda, desconhece que, após sua morte, sua obra permanecerá sob o domínio patrimonial da família por setenta anos, conforme dispõe o art. 70 da Lei. Esta especifica que o prazo passa a ser contado a partir do dia primeiro de janeiro do ano posterior ao falecimento do autor, obedecidas obviamente as questões na ordem sucessória prevista no ordenamento jurídico brasileiro (Brasil, 1998, online).

Não conhecendo o cordelista os seus direitos, torna-se possível que a gráfica responsável pela edição do acervo se aproprie do material e continue lucrando com os resultados de sua produção intelectual.

\section{Alternativas de ações na relação entre direito autoral e literatura de cordel}

O cordel, enquanto obra intelectual carece de meios mais efetivos para que o folheto, como suporte, consiga ser reconhecido como uma faceta canônica da literatura brasileira.

Tem-se observado que institutos culturais, através de seus pesquisadores, têm buscado encontrar alternativas para representar, organizar, recuperar e disseminar informações sobre os cordéis e seus produtores, garantindo-Ihes os direitos de autoria. Contudo, é difícil até mesmo disponibilizar informações de determinadas obras, por não haver condição de definir um marco inicial na linha do tempo do autor.

Com a expansão da Internet, especialmente da Web 2.0, os cordéis iniciaram um processo de hibridismo, fazendo com que a obra impressa fosse transposta para a rede.

Por isso, e aproveitando o rumo dado à Internet pelo Movimento Internacional Acesso Livre, acredita-se que os repositórios, base de dados, portais ou a bolosfera por exemplo, possam ser um caminho a ser trilhado, desde que respeitados os direitos do autor.

De uma maneira mais clara e objetiva, Oliveira e Albuquerque (2013, online) sugerem ações contributivas, a partir do projeto de pesquisa Na memória da tradição: informação sobre vida e obra de poetas populares brasileiros. O projeto propõe a divulgação das obras pela seguinte forma: (a) após 70 (setenta) anos de morte do autor: divulgação do texto na integra; (b) entre 1 (um) ano e 70 (setenta) anos após a morte do autor: solicitação de autorização da família, para divulgar a listagem de toda a produção, bem como trechos iniciais e finais da obra, tal qual o Google Livros; (c) obras com autores vivos: apenas a listagem das obras produzidas. O projeto sugere, ainda, a inclusão de link externo de acesso. 
Para aqueles que pesquisam a literatura de cordel, é cada vez mais importante encontrar ou produzir um ambiente virtual capaz de sistematizar a história, apontar os escritores, construir uma linha do tempo, possibilitando ao usuário fazer uma pesquisa eficiente frente ao inúmero contingente informacional disponível na rede que, muitas vezes, está dissociada da prática científica.

Essa estratégia de atuação não só proporcionará ao poeta popular o seu reconhecimento e valorização profissional, como também não prejudicará sua renda, que na maioria das vezes obtida exclusivamente pela venda dos folhetos de cordel.

\section{Conclusão}

Mesmo sem a pretensão de esgotar a análise sobre o campo da literatura de cordel e dos direitos autorais, entende-se ser preciso fortalecer os processos de controle bibliográfico e de depósito legal, centralizados na Biblioteca Nacional, para que se tenha resguardada a memória literária do cordel como faceta de gênero literário no Brasil.

Isso provoca a reflexão quanto à necessidade de delinear um banco nacional de cordelistas e cordéis, com o objetivo de levantar toda a produção cordelista, verificando possíveis plágios e duplicidades através de diferentes autores.

É também importante que se criem instrumentos de formação e informação para o poeta popular, com o objetivo de possibilitar-Ihe a compreensão, com mais profundidade, de seus direitos e deveres frente ao processo de produção, divulgação, comercialização e distribuição dos seus folhetos.

Vale salientar, ainda, que é preciso criar mecanismos estatais de apoio à cadeia produtiva do cordel, para que os poetas populares não se coloquem em situação de submissão diante das tipografias, gráficas e editoras que muitas vezes se apropriam de suas obras, tomando-as para si como se fossem suas e, consequentemente, desrespeitando o direito moral (autor) e patrimonial (obra).

\section{Referências}

Albuquerque, M.E.B.C. Literatura popular de cordel: dos ciclos temáticos à classificação bibliográfica. 2011. Tese (Doutorado em Letras) - Centro de Ciências Humanas, Letras e Artes, Universidade Federal da Paraíba, João Pessoa, 2011. Disponível em: <http://bdtd.biblioteca.ufpb.br/tde_busca/arquivo.php? codArquivo=1925>. Acesso em: 8 out. 2014.

Barbosa, C.R. Propriedade intelectual: introdução à propriedade intelectual como informação. Rio de Janeiro: Elsevier, 2009.

Barbosa, C.R. Propriedade intelectual enquanto informação eos aspectos econômicos dos bens intelectuais. 2007. Tese (Doutorado em Direito) - Faculdade de Direito, Universidade de São Paulo, São Paulo, 2007.

Barbosa, C.R. Relações entre informação, propriedade intelectual, jurisdição e direito internacional. 2001. Dissertação (Mestrado em Direito) - Faculdade de Direito, Universidade de São Paulo, São Paulo, 2001.

Brasil. Lei no 9.610, de 19 de fevereiro de 1998. Altera, atualiza e consolida a legislação sobre direitos autorais e dá outras providências. Diário Oficial [da] República Federativa do Brasil, Poder Executivo, Brasília, DF, 20 fev. 1998. Disponível em: <http://www.planalto.gov.br/ ccivil_03/Leis/L9610.htm>. Acesso em: 8 out. 2014.

Cascudo, L.C. Dicionário do folclore brasileiro. 12.ed. São Paulo: Global, 2012.

Fragoso, J.H.R. Direito autoral: da antiguidade à internet. São Paulo: Qpartier Latin, 2009.

Grings, L.; Pacheco, S. A biblioteca nacional e o controle bibliográfico nacional: situação atual e perspectivas futuras.
InCID: Revista de Ciência da Informação e Documentação, v.1, n.2, p.77-88, 2010. Disponível em: <http://www.revistas.usp.br/ incid/article/view/42321/45992>. Acesso em: 8 out. 2014.

Maxado, F. O que é cordel na literatura popular. Mossoró: Queima-Bucha, 2012.

Oliveira, B.M.J.F.; Albuquerque, M.E.B.C. Na memória da tradição: informação sobre vida e obra de poetas populares brasileiros. In: Encontro Nacional de Pesquisa em Ciência da Informação, 14., 2013, Florianópolis. Anais... Florianópolis: Ancib; UFSC, 2013. Disponível em: <http://enancib2013.ufsc. br/index.php/enancib2013/XIVenancib/paper/viewFile/453/ 228>. Acesso em: 8 out. 2014.

Organização Mundial da Propriedade Intelectual. Propriedade intelectual. 2013. Disponível em: <http://www.wipo.int/aboutip/en/index.html>. Acesso em: 27 jan. 2013.

Pierre, L.A.A. Direito autoral. 3.ed. São Paulo: Barros, Fischer e Associados, 2009. Disponível em: <www.resumao.com.br>. Acesso em: 17 dez. 2012.

Silva, O.S.F. Entre o plágio e a autoria: qual o papel da universidade? Revista Brasileira de Educação, v.13, n.38, p.357-414, 2008. Disponível em: <http://www.scielo.br/pdf/rbedu/v13 n38/12. pdf>. Acesso em: 4 dez. 2013.

Tavares, B. A arte do acróstico. 2008. Disponível em: <http:// www.cronopios.com.br/site/colunistas .asp?id=3322>. Acesso em: 16 fev. 2013.

Wachowicz, M.; Santos, M.J.P. (Org.). Estudos de direito de autor: a revisão da lei de direitos autorais. Florianópolis: Fundação José Arthur Boiteux, 2010. 